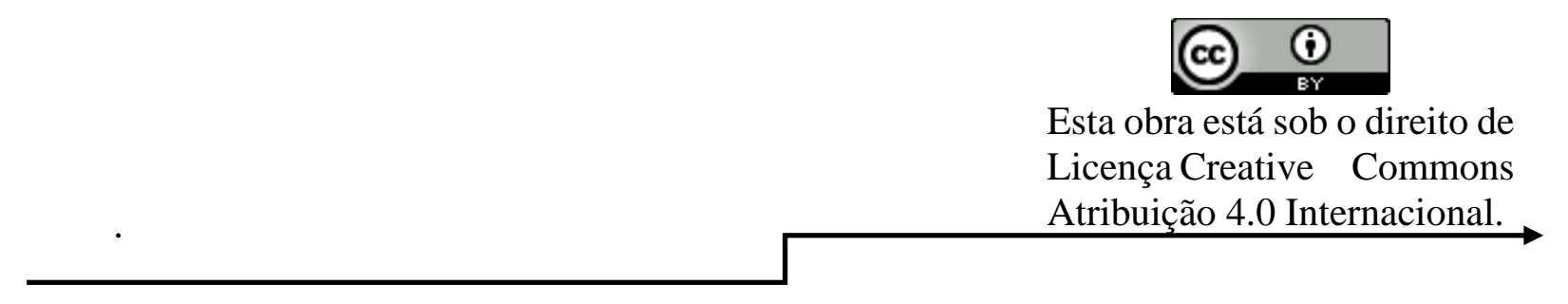

\title{
A IMPORTÂNCIA DA PARTICIPAÇÃO DA FAMÍLIA NO ÂMBITO ESCOLAR
}

\author{
Cassiane Alves Santos Bispo ${ }^{1}$ \\ Divanise Maria de Souza ${ }^{2}$ \\ Luciano Canuto Jacinto ${ }^{3}$ \\ Ivaci Bonfim Pinheiro ${ }^{4}$ \\ Maria Isabel da Silva Martins $l^{5}$ \\ Lucimairy Silva Lemos 6
}

\section{RESUMO}

Sabendo que a escola é uma parte fundamental de uma comunidade, este artigo tem como objetivo ressaltar a importância da participação da família no âmbito escolar enfatizando que para ocorrer uma educação significativa e de qualidade se faz necessário que haja a parceria família-escola. Entretanto para chegar ao melhor entendimento do tema aqui abordado foram feitas pesquisas bibliográficas, pois, a pesquisa se faz indispensável na construção de trabalhos acadêmicos já que pesquisar é executar uma investigação minuciosa com intuito de obter novos conhecimentos para assim desenvolver um trabalho relevante como também esclarecer o que antes estava obscuro podendo desta forma intervir de modo significativo. Contudo, fica evidente que a mudança tão desejada se faz com o envolvimento de todos no processo de ensino-aprendizagem visto que a escola é o complemento da família na função pedagógica cabendo a ela o papel de interagir e incentivar a busca e ampliação dos conhecimentos ao decorrer da vida escolar, enquanto a família é o alicerce, o primeiro grupo social ao qual a criança pertence, sendo esta de essencial importância no desenvolvimento intelectual e na vida escolar de nossos jovens. Portanto, à vista disso a união entre família e escola vem a contribuir de forma significativa fazendo com que haja o comprometimento de todos no desenvolvimento das nossas crianças e adolescentes, estimulando os mesmos a torna-se pessoas críticas e participativas que buscam por seus direitos e comprem com seus deveres.

Palavras - Chave: Família. Escola. Participação. Educação.

\footnotetext{
ABSTRACT

${ }^{1}$ profcassiane2014@gmail.com

${ }^{2}$ Divanisemaria@hotmail.com

${ }^{3}$ lucianocanutojacinto11@gmail.com

4 ivaci18@outlook.com

${ }^{5}$ Isabell.maria2011@gmail.com

${ }^{6}$ lucimairylemos@gmail.com
}

Knowing that school is a fundamental part of a community, this article aims to emphasize the importance of family participation in the school context emphasizing that to occur a significant and quality education is necessary to have the family-school partnership. However, in order to 
arrive at a better understanding of the subject, a bibliographical research was done, since the research is indispensable in the construction of academic papers since to research is to carry out a detailed investigation in order to obtain new knowledge in order to develop a relevant work as well as to clarify which was previously obscure and could thus intervene in a significant way. However, it is evident that the change so desired is made with the involvement of all in the teaching-learning process since the school is the complement of the family in the pedagogical function and it is the role of interacting and encouraging the search and expansion of knowledge to the as long as the family is the foundation, the first social group to which the child belongs, which is of essential importance in the intellectual development and school life of our young people. Therefore, in view of this, the union between family and school has made a significant contribution to the commitment of all in the development of our children and adolescents, stimulating them to become critical and participative people who seek their rights and buy with your duties.

Keywords: Family. School. Participation. Education. 


\section{INTRODUÇAO}

No momento atual se faz necessário que haja a valorização da participação da família no âmbito escolar. Desta forma, fica evidente a importância da parceria família e escola para que assim haja um maior conhecimento da realidade de nossos alunos, pois, sabemos que educar é estar sujeito a uma convivência vasta entre pais e professores.

É perceptível que prover a educação é muito mais do que se pode prever em uma pura execução de serviços prestados. É preciso aproximar os pais do trabalho pedagógico com a certeza da imensa diferença que essa parceria fará no processo de ensino e aprendizagem.

Contudo, é claro que temos muito a percorre nesse caminho em busca da participação ativa dos pais na vida educacional de nossas crianças e adolescentes, pois infelizmente ainda a quem acredite que a escola e feita pelos corpos docente e decente sentindo-se isentos da responsabilidade de auxiliar no processo educativo de nossos jovens.

\section{METODOLOGIA}

Quando participamos da vida escolar de nossa comunidade nos tornamos sujeitos apitos a ajudar a geração atual e as gerações futuras a descobrirem o poder
Normalmente as pessoas desconhecem o poder de transformação da realidade que acontece quando família e escola trabalham junta, daí dar-se a necessidade de se fazer campanha, palestras e reuniões para aproxima as pessoas do espaço escolar mostrando que precisamos nos unir em busca de um só objeto: a melhoria da educação, a educação de qualidade.

Certamente, esse é um trabalho árduo que requer empenho e dedicação de todas as partes envolvidas, mas vale ressaltar que, a família que participa de forma ativa da vida escolar de seus jovens torna-se influentes dentro do espaço escolar, sendo assim capazes de fazer críticas construtivas e sugestões com também capazes de defender seus direitos e cumprir com seus deveres. Portanto o Objetivo geral foi compreender a necessidade e importância da parceria família e Escola para o desenvolvimento da aprendizagem.

transformador que se dar com o processo educativo o qual é de importância impam para a construção de uma sociedade justa e democrática. É através da participação que percebemos a necessidade de estarmos 
sempre envolvidos no desenvolvimento da cidadania.

Também é por meio dela que nos tornamos sujeitos capazes de encontrar soluções para os problemas que venham a aparecer tanto na individualidade quanto na coletividade. Sendo assim, se faz necessário que a família envolva-se na construção do ensino e aprendizagem escolar do espaço de onde vive auxiliando o corpo docente a realizar seu trabalho de forma satisfatória e significativa.

Entretanto para chegar ao melhor entendimento do tema aqui abordado foram feitas pesquisas bibliográficas, pois, a pesquisa se faz indispensável na construção de trabalhos acadêmicos já que pesquisar é executar uma investigação minuciosa com intuito de obter novos conhecimentos para assim desenvolver um trabalho relevante como também esclarecer o que antes estava obscuro podendo desta forma intervir de modo significativo.

\section{Família e escola uma parceria que dar certo}

$\mathrm{Na}$ atualidade é indiscutível a importância da escola nas vidas de nossas crianças e adolescentes já que é na mesma que são construídos os conhecimentos científicos os quais cada vez mais assume uma relevância grandiosa para o sucesso pessoal e coletivo de toda a comunidade onde esses educando estão inseridos como também de todo o nosso país.

Segundo

SHINYASHIKI, (2011.p.22,23.) “... pais cobram dos professores e da escola resultados que só podem ser conseguidos quando pais, mestres e alunos atuam em conjunto". Sendo assim, se faz necessário que se reconheça a importância da parceria ativa entre a família e a escola já que o espaço escolar é o lugar depois do lar onde nossos jovens passam mais tempo.

É preciso que a família leve em conta qual valioso e importante é o interesse da mesma no processo educativo de nossos jovens.

“A participação da família na vida escolar diminui cada vez mais" (Shinyashiki, 2011, p.22.).

Contudo é papel da escola mostrar que o engajamento da família no âmbito escolar é de grande valor, pois as crianças e adolescentes precisam sentir que são prioridade na vida familiar e uma forma muito eficiente de comprovar essa importância e demonstrando interesse na vida escolar deles.

De acordo com Oliveira,

Por muito tempo, a família desempenhou o pape principal no processo de educação. À medida que o tempo passa, porém, embora continue exercendo grande influência na formação das crianças e dos jovens como grande 
agência de socialização, ela vem perdendo bastante das suas funções pedagógicas. (OLIVEIRA, 2005, p.65.)

É preciso despertar a família para que ela perceba a necessidade de voltar a exercer o papel que outrora a mesma ocupou na vida pedagógica de suas crianças e jovens. Todavia, a escola precisa estar de "porta abertas" para receber pais e responsáveis, nesse caso para se fazer um trabalho significativo se faz necessário o engajamento de todos na luta pela melhoria de nosso processo de ensino-aprendizagem. Esse despertar deve acontecer através de reuniões, debates, palestras, exposições de vídeos, leituras de mensagens e textos refletivos que levem a família a entender qual grandiosa e importante é sua participação no âmbito escolar.

\section{Limites em casa e na escola: uma demonstração de amor}

O limite é algo crucial para o crescimento intelectual e emocional de crianças e adolescentes, visto que é através do mesmo que os jovens chegam à certeza de que nem tudo que desejam fazer convém ser feito. Muitos pais sentem dificuldades em colocar limites em seus filhos à vista disso ao chegar à escola os educandos sintam-se frustrados a cada negativa dada pelos professores e demais funcionários e acabam não aceitando os limites necessários para a construção da aprendizagem.

Para ARATANGY,

... Crianças que não aprendem, desde cedo, a lidar coma frustração torna-se impacientes e birrentas, e tendem a transformar-se em adolescentes angustiados, que sofrem quando tem de suportar qualquer adiamento das satisfações. 2010.p.20.).

(ARATANGY,

Contudo, fica clara a importância e a necessidade de mostrar que o limite nada mais é do que uma prova de amor, mas o limite não pode ser imposto à força, deve-se chamar a criança ou adolescente para uma conversa franca e clara sobre o que esta acontecendo e sobre o porquê do "não", isso deve ser feito a cada situação apresentada afim de que haja o entendimento do que é certo e do que é errado mesmo que no momento de birra o jovem não demonstre entendimento e haja como se estivesse sendo injustiçado.

Sendo assim SHINYASHIKI deixa claro que:

Pode ser que o pai não aprove um projeto ou um desejo do filho, pode ser que o professor não concorde com o comportamento do aluno, mas é indispensável deixar claro que sua posição não interfere no sentimento de amor e confiança que parte dele. (SHINYASHIKI. 2011.p.89.). 
Amor irrestrito não é aquele que não põe limites, entretanto, quando se reprova o comportamento de alguém é preciso deixar claro que não se está reprovando a pessoa e sim a maneira como a mesma está se comportando para que assim o jovem venha a perceber que devemos arcar com nossos erros, pois para viver em sociedade é preciso que respeitemos as regras de convivência em todos os espaços aos quais pertencemos.

Desta forma, segundo ARATANGY,

Melhor que impor um conselho, é tentar ensinar os filhos equacionar uma situação, para que possam fazer uma escolha o mais livre possível. Isso significa ajudá-los a reconhecer a própria necessidade, apresentar com clareza as opções que existem e ajudá-los a avaliar as consequências de cada um dos caminhos possíveis. (ARANTANGY, 2010. p.28.).

Atualmente as informações sejam elas boas ou ruins chegam a uma velocidade cada vez maior, as redes sociais então ficando cada vez mais acessíveis, sendo assim agora mais do que nunca se faz necessário que limites venham a serem colocados para que crianças e adolescente não venham a caírem em armadilhas oferecidas diariamente através da internet quando usada de forma indevida e sem monitoramento de pais e responsáveis, diante disso é preciso que aconteçam conversas claras e objetivas a fim de esclarecer os perigos que os mesmos estão correndo quando acessam a sites indevidos ou conversam com pessoas a quais não conhecem.

Pois para ARATANGY,

Assim, é importante que o confronto aconteça sem que se confunda discórdia com desamor. O foco da discussão é a competência do jovem para tomar algumas atitudes Ou decisões, não sua capacidade de pensar. O que está em jogo é sua integridade física não o afeto dos pais. (ARATANGY, 2010. p. 21.).

Sabemos que mesmo nos dias atuais muitos pais continuam leigo no que diz respeito ao assunto internet e redes sociais, contudo, o professor deve conversar com seus alunos sobre o assunto fazendo com que os mesmos venham a perceber e entender que é preciso cautela com o uso da internet e das redes sociais.

Contudo o diálogo é a chave do entendimento sendo de essencial importância para a construção da confiança a qual deve ser alimentada diariamente fazendo com que os jovens entendam que os adultos têm mais tempo de vivencia e assim adquiriu experiências à vista disso podem aconselhá-los alertando e protegendo-os, mais, para que esse entendimento venha a ocorrer se faz indispensável à parceria família, escola. 


\section{CONSIDERAÇÕES FINAIS}

Diante das pesquisas feitas para a realização desse trabalho podemos afirmar a importância da participação da família no âmbito escolar, desta forma, é preciso fazer com que a mesma venha a reconhecer a necessidade de estar envolvida no processo de ensino e aprendizagem de seus filhos mostrando as nossas crianças e adolescentes que podem estar seguros de que seus genitores então interessados em seu desenvolvimento intelectual e social, a fim de que os mesmo sintam-se seguros e incentivados para realizar "voos" cada vez mais altos em direção ao sucesso tanto na vida escolar quanto na vida em sociedade.

À vista disto, é preocupante o fato de que mesmo nos dias atuais ainda existam pais que acreditam que a questão educacional é responsabilidade somente da escola sentindo-se isentos da obrigação de educar seus filhos. Sendo assim, é gritante a necessidade do esclarecimento desta questão já que é dever da família cuidar, educar, proteger e orientar suas crianças e adolescentes ficando à escola incumbida de reforçar os valores aprendidos no seio familiar como também da construção do conhecimento científico e do desenvolvimento intelectual.

Contudo, a escola deve estar sempre de "portas aberta" para receber a família visto que, fica cada vez mais evidente a necessidade da efetivação da parceria família-escola para o desenvolvimento de ações pedagógicas que levem a um ensino onde mais do que conteúdos científicos abordem valores humanos como a ética e cidadania. Desta forma, cabe à mesma convidar os pais a participar da vida escolar de suas crianças e adolescentes fazendo com que haja o entendimento de sua importância para o desenvolvimento de um trabalho com eficiência, pois a família é o primeiro grupo social ao qual a criança é inserida sendo assim sua presença insubstituível e de grande valia para seu desenvolvimento fazendo com que ela sente-se amada, incentivadas e protegidas.

Contudo, é preciso conhecer a vida dos educando e isso só acontece quando conhecemos sua família, a comunidade onde vive e os grupos sociais aos quais pertence, pois como o uso incorreto das redes sociais, o aumento do uso de droga e da prostituição infantil é cada vez mais crescente e preocupante a criminalidade envolvendo crianças e adolescentes.

Sendo assim, é indispensável que saibamos o que ocorre além dos murros da escola e para isso devemos orientar nossos jovens quanto aos perigos que estão correndo com o uso inadequado da internet e como o envolvimento com pessoas ligadas ao crime, essa orientação deve ser feita através de conversas francas e abertas 
mostrando que eles podem confiar e dividir seus medos e angustias com seus pais e professores sem que seus erros sejam apontados ou julgados.

À vista disso é preciso o envolvimento da família nas ações pedagógicas para que assim os pais venham a ser conhecedores do que está acontecendo na escola como também a escola venha, a saber, o que ocorre com esses jovens quando os mesmos encontram-se fora do espaço escolar, formando assim uma correte de proteção e interesses em comum, pois fica cada vez mais claro que somente trabalhando em parceria teremos a transformação de nossas escolas e com isso de nossos educandos.

\section{REFERENCIAS}

ARATANGY, Lídia Rosenberg. Novos desafios da convivência. São Paulo: Rideel, 2010.

CURY, Augusto. Pais brilhantes, professores fascinantes. Rio de janeiro: Sextante, 2008.

FREIRE, Paulo. Professora sim, tia não cartas a quem ousa ensinar. São Paulo: Olho d'água, 2001. Ação cultural para a liberdade. São Paulo: Paz e Terra, 2001(a,b...).
Sabemos que há um longo caminho a ser percorrido para assim conseguir alcançar uma educação significativa e de qualidade onde família e escola caminham juntas formando assim cidadãos capazes de transformar suas próprias realidades e com isso a realidade de todos que os cercam.

Portanto, vale ressaltar que essa é uma batalha que merece ser encarada com garra e determinação, pois só assim conseguiremos transformar a realidade dos nossos alunos, de suas famílias, de nossas escolas, da comunidade na qual a escola está inserida, como também de toda a sociedade a qual fazemos parte.

\section{, Pedagogia da autonomia. São Paulo: Paz e Terra,1996. \\ OLIVEIRA, Pérsio Santos de. Introdução à sociologia da educação. São Paulo: Editora Ática, 2005.}

RYAN, M.J. (Mary Jane). O poder da paciência. Rio de Janeiro: Sextante,2009.

SHINYASHIKI, Roberto. Conquiste seus alunos. São Paulo: Editora Gente, 2011.

VON IHERING, Rudolf. A luta pelo direito. Rio de Janeiro: Forense, 2004. VASCONCELOS, Ana. Manual completo de sociologia. São Paulo: Rideel, 2010. 